\title{
The pitfalls of the traditional office ergonomics model in the current mobile work environment: Is visual ergonomics health literacy the remedy?
}

\author{
Jennifer Long ${ }^{\mathrm{a}, \mathrm{b}, *}$ and Hans Richter ${ }^{\mathrm{c}}$ \\ ${ }^{a}$ Jennifer Long Visual Ergonomics, Katoomba, NSW, Australia \\ ${ }^{\mathrm{b}}$ School of Optometry and Vision Science, UNSW Sydney, NSW, Australia \\ ${ }^{\mathrm{c} C e n t r e ~ f o r ~ M u s c u l o s k e l e t a l ~ R e s e a r c h, ~ D e p a r t m e n t ~ o f ~ O c c u p a t i o n a l ~ a n d ~ P u b l i c ~ H e a l t h ~ S c i e n c e s, ~}$ \\ Faculty of Health and Occupational Studies, University of Gävle, Gävle, Sweden
}

Received 24 January 2019

Accepted 2 February 2019

\begin{abstract}
Mobile technology has revolutionised how we work. It is now relatively easy to work anywhere and anytime, but this has placed the onus is on mobile (or flexible) workers to set up their own work environment for comfort and ease of use. Vision is an important driver of posture, and hence visual ergonomics principles are integral for setting up digital devices. If mobile workers do not have visual ergonomics knowledge, or are unable to apply visual ergonomics knowledge to appropriately set up their work environment, then they are at risk of developing visual-related occupational health issues due to exposure to adverse physical work environments. To address this potential health care issue, we propose the introduction of Visual Ergonomics Health Literacy. This would provide mobile workers (including school children) with the knowledge and skills to set up their work environment for comfort and ease of use, wherever they work. It is important to address this issue now before we have a widespread epidemic of discomfort and injury from not applying sound visual ergonomics principles to work environments.
\end{abstract}

Keywords: Computer, smartphone, visual displays, lighting, design

\section{Modern ways of working and the pitfalls of the traditional office ergonomics model}

Mobile technology has revolutionised how we work. It is now relatively easy to work anywhere and at any time.

*Address for correspondence: Jennifer Long, Jennifer Long Visual Ergonomics, PO BOX 645, Katoomba, NSW 2780,

Australia. E-mail: jlong@ visualergonomics.com.au.
A major consequence is that office workers are no longer constrained to a designated workstation. Activity based work areas are a feature of many offices, allowing workers the flexibility to work from a variety of workstations according to their task. Workers may also have the flexibility to work from home, in transit and in vehicles, or be required to work from digital devices in-the-field. In some cases, workers are termed "nomadic" if they travel most of their work time to meet and/or collaborate 
with others inside and outside of their organisation [1].

These new ways of work pose several new and interrelated challenges for occupational health and ergonomics.

Firstly, the traditional office ergonomics model assumes that an individual has their own workstation and chair. With the assistance of an ergonomics advisor, their workstation can be optimised for comfort by making adjustments to the workstation or chair, or by providing ancillary equipment such as document holders and footrests [2]. However, if a worker does not have a designated workstation, or if their work locations are transitory, then it is not feasible to provide individual ergonomics advice for each of their work locations.

Secondly, the traditional office ergonomics model assumes that a worker has a relatively constant exposure to elements at their workstation. For example, if the worker has a short stature, then their feet may not reach the floor when seated at their workstation. If the adverse element is addressed (in this case, by the provision of a footrest) then the worker's comfort will improve. However, if a worker uses multiple work areas throughout the day, then they may be exposed to a variety of different elements which hinder their performance or comfort. This can pose a challenge for ergonomists and rehabilitation workers who need to isolate the cause of discomfort in an injured worker.

Thirdly, mobile (or flexible) work environments have shifted the onus onto workers to set up their own work area for comfort. Workers need to have an awareness of ambient light, noise, airflow and temperature, particularly when these parameters affect their ability to work comfortably and easily. They also need to have the resources and ability to make modifications to improve their work environment [3]. Although this sounds straightforward, it may be limited by a worker's ability to identify deficient elements in their environment or by their motivation to modify their work environment [4]. It may also be hampered by the remarkable ability of humans to adapt to and continue to work in deficient work conditions, even if it has poor consequences for their health or comfort, for example, adjusting one's posture to see around a reflection on a computer display [5].

Vision is an important driver of our posture [6, 7]. This has implications for contemporary digital device usage: if a work environment does not facilitate good vision and good visual ergonomics, then there is an increased risk that a worker will adopt awkward postures to see their work [6], experience visual discomfort (also referred to as computer vision syndrome) [8], or be less productive [9].

The purpose of this article is to provide an overview of visual ergonomics issues related to mobile work environments, identify some of the gaps in our knowledge, discuss potential opportunities for incorporating visual ergonomics principles within design standards, and propose the concept of visual ergonomics health literacy as a way to mitigate the physical challenges associated with mobile working.

\section{Visual ergonomics and mobile work environments}

There are many visual ergonomics issues associated with mobile work environments. In this article they are grouped into the following categories: device location (viewing height and horizontal location relative to the user), display characteristics (font size), lighting (reflections, glare and ambient light), agerelated needs (older age workers, children and youth) and rest breaks.

\subsection{Viewing height}

The human eye's ability to converge and to focus its crystalline lens to see an object at a near distance is better when looking in a downward gaze compared to an upward gaze [10]. This has implications for the vertical location of digital displays: if a computer display is located above eye height then a worker is more likely to tip their head backwards to view the display $[6,7]$, increasing their neck flexion, which in turn can contribute to physical discomfort. The literature reports that visual and physical comfort can be improved if visual displays are below eye height $[6,7]$ but they should not be located so low that it induces increased neck flexion and head tilt to view the display $[11,12]$.

Portability is a key feature of mobile devices. One way this is achieved is by locating the input area (e.g. keyboard, touch screen) in close proximity to the visual display. This then poses a dilemma for the user. If they choose to maintain a comfortable arm posture, then they will need to flex their head and neck forward to view the display, as has been shown to occur with laptop computers [11], tablets [13] and smartphones [12, 14] (see Fig. 1). If the user opts for a comfortable head and neck posture by holding the 


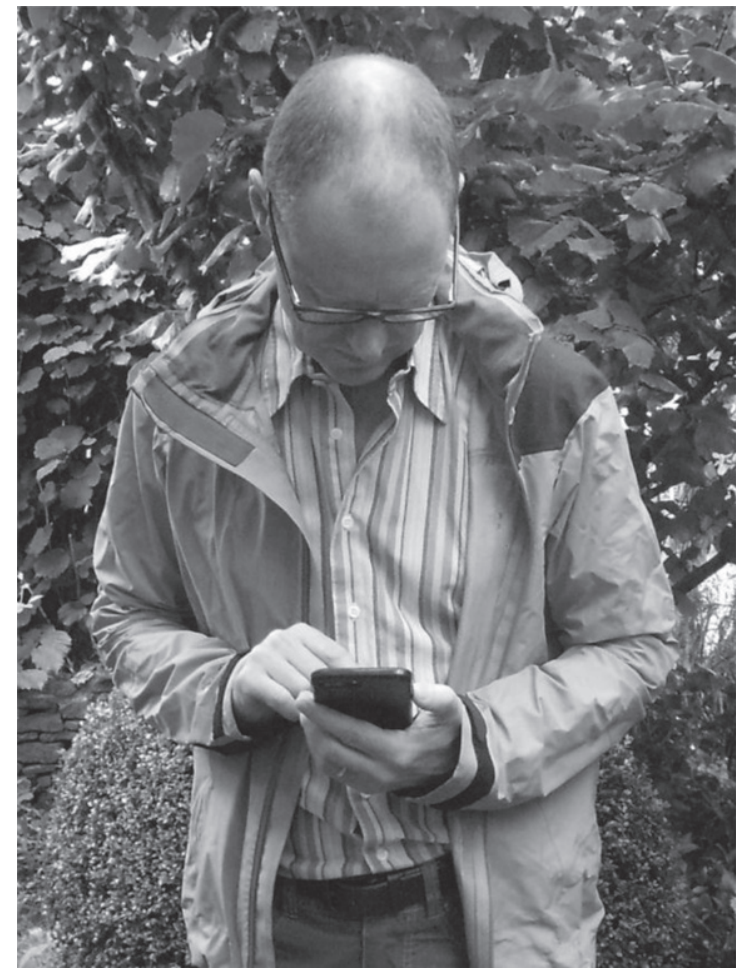

Fig. 1. Head flexed forward to maintain a comfortable arm posture when using a digital device.

device higher, then there is increased static muscular load on their shoulders and arms [5] (see Fig. 2).

It is possible to separate (or de-link) the input and visual display area to facilitate good physical and visual posture. For example, when working with a laptop, use a laptop-station together with an external keyboard and mouse [15] (see Fig. 3). However, making these modifications means that the user needs to purchase and carry additional accessories. These accessories will add to the weight and bulk of what needs to be carried, which can negate the advantage of having a portable device [5].

\subsection{Horizontal location of devices}

There have been studies investigating the postural implications for the horizontal location of portable devices with desktop computer monitors. For example, Szeto and co-authors demonstrated increased static muscle activity in the neck and shoulder muscles of subjects who turned their head to view an angled computer monitor for 20 minutes [16] but less static muscle activity when subjects actively worked between dual computer monitors [17]. Szeto pos-

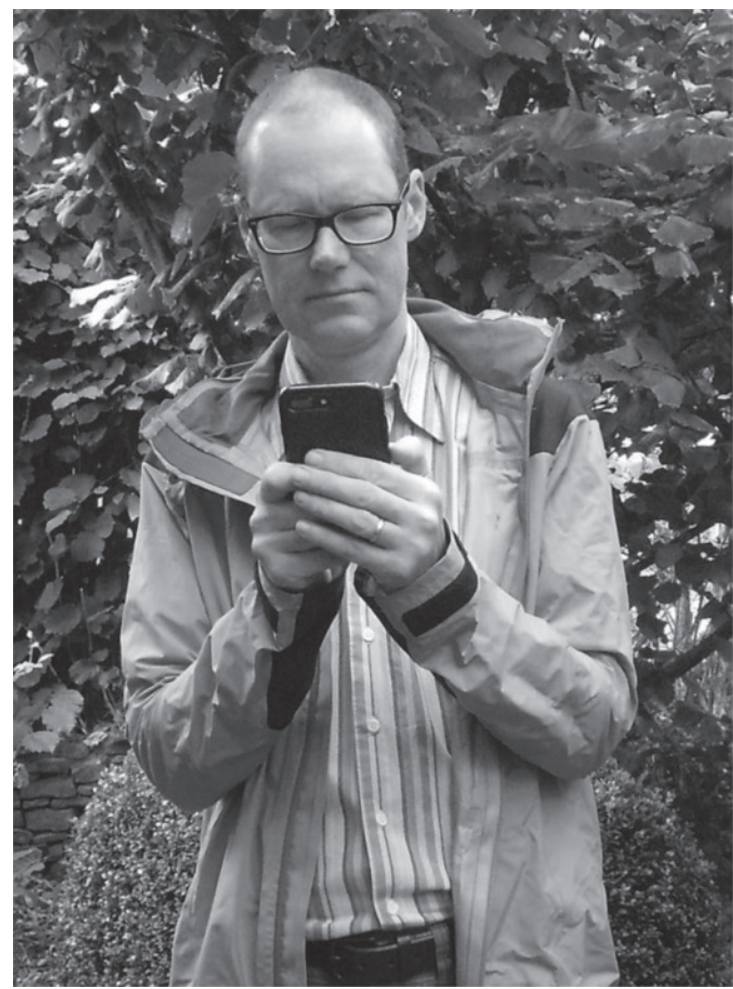

Fig. 2. A more comfortable head and neck posture when using a digital device increases the static load on the shoulders and arms.

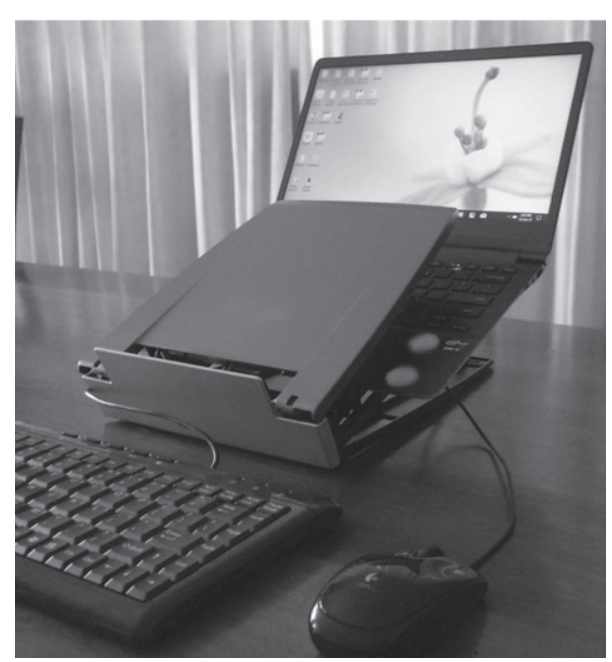

Fig. 3. Example of a laptop-station with external mouse and keyboard.

tulates that varying the head posture to view dual desktop monitors may reduce static muscle tension in the shoulder and the neck [17].

Szeto's dual monitor work [17] augers well for people who concurrently work from multiple digital 


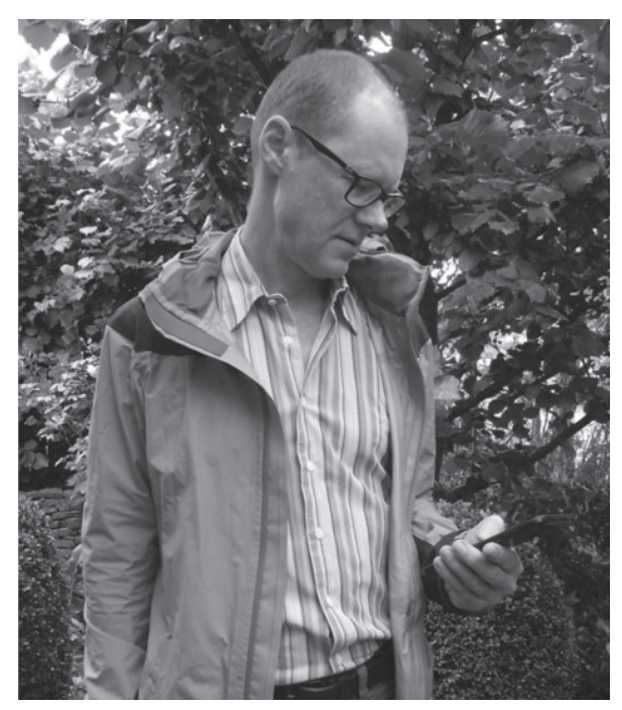

Fig. 4. Holding a digital device in one hand to the side of the body can induce a subtle head turn in order to view the device.

devices, such as a laptop, tablet and smartphone the dynamic head motion required to view multiple devices may reduce the risk of musculoskeletal discomfort. Similarly, Szeto's angled computer display work [16] has implications for people who hold a digital device (such as a smartphone or tablet) in one hand to the side of the body, requiring a subtle head turn to view the device (see Fig. 4). This may increase the static muscular load in the neck and shoulders and contribute to physical discomfort, particularly if the device is used for prolonged periods. Both these issues require further investigation with people using mobile digital devices.

\subsection{Size of display characters}

If a person views small size characters on a visual display, then they have two options: maintain a long viewing distance with the risk of not being able to discern detail within the characters (i.e. the character size is too small to read) or make a postural adjustment to increase the character's angular size on the eye's retina (i.e. so that the character size is large enough to read). The latter can be achieved by a person moving their head and torso closer to the desktop display $[18,19]$ or by holding the display at a close viewing distance [20].

There is evidence that the small size font displayed on handheld devices such as smartphones drives users to hold the device at a close viewing distance [20] and that this can contribute to visual discomfort [21].
There is also evidence that small size font can affect productivity, but this has only been demonstrated for desktop computer displays [22].

To achieve portability, many mobile devices have a small visual display. Therefore users are faced with a trade-off between enlarging the font size so that it is comfortable to read versus reducing the font size so that they can view the entire screen page without excessive scrolling. Short of ensuring that digital interfaces are designed to maximise font size AND usability (which will be discussed in section 3 on design strategies), if an individual needs to read from their device for prolonged periods then they should use a larger size device which allows them to view a larger size font [5].

\subsection{Lighting}

A convention for lighting design in office environments is to locate overhead luminaires to the side of workstations [23]. In this way, luminaires are not located in front of or above the worker, shining in their eyes and creating discomfort from direct glare $[24,25]$. Nor are the luminaires directly behind the worker casting shadows on the workstation [26] or producing specular or diffuse reflections on the computer displays which can reduce contrast and task visibility and contribute to visual discomfort [27].

There is some evidence that visual discomfort associated with glare may be a contributing factor for neck and shoulder pain [25]. There are also descriptions within the literature of how users modify their posture in the presence of glare and reflections. For example, Tegtmeier [5] describes how touchscreen and tablet users made postural adjustments and tilted their digital devices to avoid reflected glare on the device. Similarly, there are experimental studies which report that some users change their viewing distance in the presence of reflected glare on a computer display [22, 28]. Ko and co-authors report in their experiments that reflective glare did not have a significant effect on productivity [22], but Shieh reports that subjective visual fatigue was rated as worse in the presence of reflections [28].

The second design convention is to not have large differences in luminance contrast between objects; otherwise the brightness difference between objects can be distracting [26] and contribute to visual discomfort [29]. Examples of non-optimal conditions which could be experienced by mobile workers include working near windows or luminaires which are significantly brighter than the digital display, or 
the reverse: using a digital display in low light conditions where the display is significantly brighter than the surroundings. In a study comparing smartphone use in dark versus lit conditions, visual symptoms and eye discomfort was greater when reading from a smartphone in the dark [30]. Antona and coauthors comment that although smartphone devices may have an auto-brightness function which automatically adjusts the screen luminance to match the ambient lighting conditions, they have observed that the screen luminance is too great when using the smartphone in the dark [30].

Discomfort associated with lighting is potentially worse when working in cafes, in vehicles on in transit (e.g. on trains, planes, airport lounges). This is because chairs and tables used by workers might not be optimally placed relative to overhead luminaires, or the ambient light might be unpredictable or quickly change, for example, if travelling in a vehicle which has direct sunlight streaming through the window in some directions of travel. Unlike an office environment where these problems may be solved by appropriate location of furniture or by installing window blinds [25], mobile workers have less control over these aspects of their environment.

Discomfort from lighting can also be an issue for people working from home where there may be a conflict between the task lighting requirements to perform work and the aesthetic requirements for home lighting. A home based worker may be unable to modify the lighting to improve their visual comfort and ability [3] or for aesthetic reasons they may not wish to change their home lighting.

\subsection{Older age workers}

As we age, our ability to accommodate (change focus between viewing distances) decreases. This is called presbyopia, and typically manifests at about the age of 40 as a difficulty focussing at close distances. Presbyopia can be corrected with spectacles or contact lenses.

General purpose progressive lenses and general purpose bifocals are contraindicated for desktop computer monitors because they promote a chinup/head-forward posture for the wearer in order to see through the reading portion of their spectacles [31]. This can contribute to physical discomfort from an increased postural load in the neck and shoulder region [32].

As yet there are no publications reporting comfort and ability for people with presbyopia using handheld mobile devices, but logic suggests that if the device is held in the reading plane (i.e. where one would hold a book to read) then general purpose progressive and bifocal lenses would be suitable for use, just as they are for reading books. The key difference between reading from hardcopy documents and reading from small devices such as smartphones is the viewing distance: hardcopy documents are typically held about $40 \mathrm{~cm}$ from the eyes, whereas smartphones may be held at $35 \mathrm{~cm}$ or less [20,21]. Therefore, if an olderage worker reads from the phone at a close viewing distance, then they may require a stronger prescription in their spectacles to clearly see the display.

The other major consequence of aging is our response to light, for example, a need for more light to see detail, colour and contrast, and an increased risk of ocular health disorders such as cataracts which can contribute to increased sensitivity to bright light sources [33]. There are also age-related physiological and neural changes which slow our dark adaptation as we get older: a study of 94 adults without ocular disease showed that 70 year olds can take up to 10 minutes longer to adapt to dark conditions after being in lit conditions compared to 20 year olds [34]. Prolonged glare recovery after exposure to a bright light can impact the ability to discriminate contrast (i.e. detect a dark object against a light background, as required for reading) [35] and may be even more prolonged in the presence of ocular diseases such as macular degeneration [36]. These changing responses to light are potential issues for all workers, but may be more problematic for mobile workers who have less ability to control their working environment.

\subsection{Children and youth}

School children can also be classified as mobile workers because they work at multiple locations throughout the day, for example, in the classroom, library, school grounds, in transit and at home. One of the biggest challenges for ensuring that children are comfortable when using computers and other digital devices is providing and selecting appropriate size furniture for them $[37,38]$ and, if the furniture is adjustable, then ensuring that it has been correctly adjusted for their size [37]. This has implications for the location of visual displays relative to the eye height of the child.

There is very little literature reporting the effect of digital device use on the vision and ocular health of children and teenagers [39], despite reports that 
children as young as 2 years use digital devices [40]. Associations have been reported between smartphone/computer use and dry eye in children [41] (see section 2.7 below).

One issue which has recently captured attention in the scientific literature is a possible link between myopia and sunlight exposure. For many years there has been debate whether myopia has a genetic basis or is the result of environmental exposures such as performing close work [42]. High proportions of myopia have been linked to education levels [42] with associated blame on using digital devices. Emerging evidence indicates that childhood myopia can be slowed by spending time outside in daylight [43] and there is conjecture that increasing the amount of daylight through school windows may reduce the risk [44]. So far, this evidence applies to myopia in children, not adults. This research has implications for children using digital devices: if children are encouraged to work outside, then they will need to be mindful of postural and lighting issues as discussed in sections 2.1 to 2.4 above.

\subsection{Rest breaks}

Much of the rest break literature for computer use relates to data-entry type tasks performed on a desktop computer. This body of knowledge has demonstrated that eye and vision comfort can be improved by taking rest breaks without any decrement in productivity or performance [45-47]. The rest break schedules reported in these experiments include 5 minute breaks every 30 minutes [47], a micro-break every 15 minutes [47], 30 second breaks every 15 minutes and 3 minute breaks every hour [46] and regular breaks scheduled over an 8 hour period [45].

Although these data provide a guideline for the frequency with which people should take rest breaks from computer work, data entry tasks are not the only way people use a computer. This is particularly so in 2019 where people may use multiple digital devices to access information, interact with social media, send and receive emails, perform creative work (e.g. write, draw), read books, watch videos and play games. Further, when taking a rest break from their formal work, people may use other digital devices such as smartphones or tablets to engage in these myriad activities.

There is evidence that 60 minutes continuous reading from a smartphone is associated with visual discomfort [21] and ocular surface disorders such as dry eye [48]. There also appears to be an association with hours of smartphone / computer use and dry eye in children [41] but this work only reports total hours use per day, not continuous use. The impact of intermittent device use and multiple device use on visual comfort and ocular health and the maximum recommended use time requires further investigation [21, 39].

\section{Design strategies to mitigate discomfort and optimize productivity}

One way to mitigate the visual ergonomics health and performance problems associated with mobile work is to design equipment which facilitates comfortable and effective use. For example, set the default font size on digital devices to $3.6 \mathrm{~mm}$ because this has been shown to improve productivity, accuracy and ease with performing computer tasks [22] or include an adaptive feature on digital displays which automatically adjusts the luminance contrast between text and the background to assist reading comfort [49]. These types of engineering controls would remove or at least minimise the burden placed on workers to adjust their workstation and display for optimal comfort and use.

Creating design standards would require a body of evidence-based literature to support the design parameters. This is within the realm of possibility because there are already publications which report links between visual posture, comfort and productivity (as described in section 2). These design standards could be used as a benchmark for manufacturers when designing new equipment [50].

Despite this, there remains a risk that users will override default settings on equipment (for example, make the font size smaller) or use devices in nonrecommended ways (for example, view their digital device with a sustained head-turn posture).

Therefore, in addition to implementing strategies to improve the design of digital devices, we also need to communicate recommended practice guidelines to end users so that they can make informed choices when working in varied environments [50]. This could be termed "visual ergonomics health literacy".

\section{Visual ergonomics health literacy}

The World Health Organisation defines health literacy as "the cognitive and social skills which 
determine the motivation and ability of individuals to gain access to, understand and use information in ways which promote and maintain good health" [51]. People with low health literacy are more likely to have difficulty understanding and assimilating health information, for example, being able to read the label of a prescribed drug [52]. Low health literacy is associated with poorer health outcomes and higher mortality, increased health costs for individuals and in the United States, 3-5\% additional cost to the healthcare system [52]. Conversely, high health literacy is associated with better health outcomes.

It is estimated that $60 \%$ of Australian adults have low health literacy, and that this is similar to health literacy estimates in other developed countries [52]. Although we have no specific knowledge about visual ergonomics health literacy within world populations, there is evidence that the general population only has limited knowledge of vision and eye care issues and limited awareness of eye disease [53].

Improving health literacy entails more than providing health education to an individual. Instead, health literacy considers an individual within a social, environmental and political context and encourages an individual's active participation in their healthcare $[51,52,54]$. As such, health literacy is not only the responsibility of individuals, but includes all stakeholders within the health system, such as healthcare providers, organisations that provide healthcare services, government bodies, regulators and policy makers [52] to ensure a consistent message is communicated to end users. In the context of work, health literacy could also include the employer who is obligated to provide safe and healthy work conditions for employees.

Visual ergonomics is a particular challenge because digital technology is developing at a fast pace and people interact with devices in a wide variety of ways [55]. Although guidelines exist for healthy use of digital devices, for example, notebook personal computers [56], computers for use by children [57], electronic games for use by children [58], it is difficult to predict future forms of technology and the ergonomics challenges these may pose. Hence it is difficult to develop prescriptive advice which can be applied to all the different ways people may interact with devices and to future technology designs.

If the end user has visual ergonomics knowledge (and by extension, visual ergonomics health literacy) then there is potential for them to apply basic visual ergonomics principles to future and novel work scenarios. This concept is similar to the par- ticipatory ergonomics philosophy whereby workers become ergonomics literate and have the skills to become their "own ergonomist", are able to make appropriate ergonomics interventions for current and future problems within their workplace, are aware of their knowledge limitations and are therefore able to seek additional help when necessary [59]. Although this type of strategy has been reported as successful for office workers $[60,61]$ and for teaching healthy computing skills to school children [62], Hägg cites an example of workers becoming injured when ergonomics information was misapplied: therefore, if workers are being their "own ergonomist", then they needs to have access to good quality ergonomics knowledge and understand how to apply it correctly [61].

\section{Future work}

In light of the challenges outlined in this article, we propose that visual ergonomics health literacy is imperative if we are to avoid increased health costs associated with mobile working environments. We propose "visual ergonomics" health literacy rather than simply "ergonomics" health literacy because many of the awkward postures associated with digital device use are linked to how a person looks at the visual display. We also believe that if a person has an understanding of basic visual ergonomics principles (some of which were outlined in section 2) then they will be able to apply these principles wherever and whenever they use their digital devices.

Teaching people visual ergonomics principles after they commence employment is too late. If infants use devices, then the education should commence at that age. Similarly, if school children use digital devices, then visual ergonomics principles should be reinforced during the school years. But to achieve this goal, parents, caregivers and teachers need to have good visual ergonomics health literacy themselves so that they can share accurate information with the children. A similar argument was put forward by Legg and Jacobs in their article supporting the introduction of ergonomics education modules within teacher training colleges [63].

This is not to say that it is redundant to reinforce visual ergonomics principles after people commence employment. If people are familiar with the concepts from a young age, then it might gain more traction within workplaces if the visual ergonomics principles are presented in terms of work efficiency or if 
they are integrated within general company policies, rather than only badged as "health and safety". Similar sentiments have previously been proposed for general ergonomics [61]. This approach is also consistent with health literacy principles which advocate a three pronged strategy: embedding health literacy into systems, ensuring effective communication and integrating health literacy into education [52].

This article has presented an argument for visual ergonomics health literacy, based on the success of general health literacy programs. Further research is required to progress this concept. For example:

- How can we define visual ergonomics health literacy? Is it an ability to adjust the computer display settings or use a digital device correctly? Wearing appropriate spectacles (or spectacles with the correct focusing power) when using a visual display? Having a regular eye examination? Appropriate care for a chronic eye condition?

- What is the current visual ergonomics health literacy of the population?

- What is the best way to promote visual ergonomics health literacy to the broader population? How can individuals be motivated to improve their visual ergonomics work conditions?

- How can we measure the success of any interventions? Should we measure a reduction in eye/visual musculoskeletal health problems? An improvement in eye/neck comfort or work satisfaction? An improvement in efficiency or productivity?

- Can we develop a business case to demonstrate the cost-benefits of visual ergonomics health literacy?

- Can some of the burden for good visual ergonomics work conditions be shifted from the individual to the designers of equipment or work areas?

\section{Conclusion}

The foundation underpinning many of the visual ergonomics principles we apply to today's technology were established several decades ago. These principles can be used to prevent discomfort and injury, improve health and increase work performance.
Office workers in "traditional" offices with designated workstations may benefit from this knowledge by having ergonomics assistance to adjust their workstation, or they may be exposed to ergonomics guidelines or information through education programs within their workplace. Unfortunately, this time-honoured visual ergonomics knowledge is not reaching a new and rapidly growing body of the population who use digital devices in mobile (or flexible) environments. Consequently, these people are at risk of developing visual-related occupational health issues due to exposure to adverse physical work environments.

There is scope for incorporating visual ergonomics principles into the design of devices to improve comfort and efficiency. However, if digital device use is ubiquitous, then individuals require the knowledge (and the motivation) to improve their own visual ergonomics work conditions. It is important to address this now before we have a widespread epidemic of discomfort and injury from not applying sound visual ergonomics principles to work environments.

\section{Acknowledgment}

The views expressed in this article are those of the authors and do not necessarily represent those of the School of Optometry and Vision Science, UNSW Sydney Australia or Centre for Musculoskeletal Research, University of Gävle, Sweden.

\section{Conflict of interest}

None to report.

\section{References}

[1] Mark G, Su N. Making infrastructure visible for nomadic work. Pervasive and Mobile Computing. 2010;6:312-23.

[2] Goodman G, Landis J, George C, McGuire S, Shorter C, Sieminski M, et al. Effectiveness of computer ergonomics interventions for an engineering company: A program evaluation. Work. 2005;24:53-62.

[3] Janneck M, Jent S, Weber P, Nissen H. Ergonomics to Go: Designing the mobile workspace. International Journal of Human-Computer Interaction. 2017. https://doi.org/10. 1080/10447318.2017.1413057.

[4] Tims M, Bakker A. Job crafting: Towards a new model of individual job redesign. SA Journal of Industrial Psychology. 2010;36(2):Article \#841. DOI: 10.4102/sajip.v36i2.841 
[5] Tegtmeier P. A scoping review on smart mobile devices and physical strain. Work. 2018;59:273-83.

[6] Villanueva M, Sotoyama M, Jonai H, Takeuchi Y, Saito S. Adjustments of posture and viewing parameters of the eye to changes in the screen height of the visual display terminal. Ergonomics. 1996;39(7):933-45.

[7] Burgess-Limerick R, Mon-Williams M, Coppard V. Visual Display Height. Human Factors. 2000;42(1):140-50.

[8] Gowrisankaran S, Sheedy J. Computer vision syndrome: A review. Work. 2015;52:303-14.

[9] Hedge A, Sims W, Becker F. Effects of lensedindirect and parabolic lighting on the satisfaction, visual health and productivity of office workers. Ergonomics. 1995;38(2):260-80.

[10] Ripple P. Variation in accommodation in vertical directions of gaze. American Journal of Ophthalmology. 1952;35:1631-4.

[11] Straker L, Jones K, Miller J. A comparison of the postures assumed when using laptop computers and desktop computers. Applied Ergonomics. 1997;28(4):263-8.

[12] Namwongsa S, Puntumetakul R, Neubert M, Boucaut R. Factors associated with neck disorders among university student smartphone users. Work. 2018;61:367-78.

[13] Young J, Trudeau M, Odell D, Marinelli K, Dennerlein J. Touch-screen tablet configurations and case-supported tilt affect head and neck flexion angles. Work. 2012;41:81-91.

[14] Lee S, Kang H, Shin G. Head flexion angle while using a smartphone. Ergonomics. 2015;58(2):220-6.

[15] Berkhout A, Hendriksson-Larsen K, Bongers P. The effect of using a laptopstation compared to using a standard laptop PC on the cervical spine torque, perceived strain and productivity. Applied Ergonomics. 2004;35:147-52.

[16] Szeto G, Sham K. The effects of angled positions of computer display screen on muscle activities of the neckshoulder stabilizers. International Journal of Industrial Ergonomics. 2008;38:9-17.

[17] Szeto G, Chan C, Chan S, Lai H, Lau E. The effects of using a single display screen versus dual screens on neck-shoulder muscle activity during computer tasks. International Journal of Industrial Ergonomics. 2014;44:460-5.

[18] Rempel D, Willms K, Anshel J, Jaschinski W, Sheedy J. The effects of visual display distance on eye accommodation, head posture, and vision and neck symptoms. Human Factors. 2007;49:830-8.

[19] Long J. The effect of character size on working distance at a computer screen. In: Blewitt V, editor. Ergonomics for Life: At work, home and leisure; 8-11 October 2000; Adelaide: Ergonomics Society of Australia Inc; 2000, pp. 40-5.

[20] Bababekova Y, Rosenfield M, Hue J, Huang R. Font size and viewing distance of handheld smart phones. Optometry and Vision Science. 2011;88(7):795-7.

[21] Long J, Cheung R, Duong S, Paynter R, Asper L. Viewing distance and eyestrain symptoms with prolonged viewing of smartphones. Clinical and Experimental Optometry. 2017;100(2):133-7.

[22] Ko P, Mohapatra A, Bailey I, Sheedy J, Rempel D. Effect of font size and glare on computer tasks in young and older adults. Optometry and Vision Science. 2014;91(6):682-9.

[23] Department of Employment and Industrial Relations Working Environment Branch. Artificial Light at Work. Canberra: Australian Government Publishing Service; 1984.

[24] Ngai P, Boyce P. The effect of overhead glare on visual discomfort. Journal of the Illuminating Engineering Society. 2000;Summer:29-38.
[25] Helland M, Horgen G, Kvikstad T, Garthus T, Aaras A. Will musculoskeletal and visual stress change when visual display unit (VDU) operators move from small offices to an ergonomically optimized office landscape. Applied Ergonomics. 2011;42(6):839-45.

[26] Osterhaus W, Hemphala H, Nylen P. Lighting at computer workstations. Work. 2015;52(2):315-28.

[27] Collins M, Goode A, Atchison D. The effectiveness of computer screen filters. Clinical and Experimental Optometry. 1993;76(3):91-100.

[28] Shieh K-K. Effects of reflection and polarity on LCD viewing distance. International Journal of Industrial Ergonomics. 2000 2000;25:275-82.

[29] Grandjean E. Fitting the Task to the Man. 4th Edition ed. London: Taylor \& Francis; 1988.

[30] Antona B, Barrio A, Gasco A, Pinar A, Gonzalez-Perez M. Symptoms associated with reading from a smartphone in conditions of light and dark. Applied Ergonomics. 2018;68:12-7.

[31] Long J. Prescribing for a computer user. In: Rosenfield M, Lee E, Goodwin D, editors. Clinical Cases in Eye Care. Philadelphia: Wolters Kluwer; 2019, pp. 40-3.

[32] Horgen G, Aaras A, Fagerthun H, Larsen S. Is there a reduction in postural load when wearing progressive lenses during VDT work over a three-month period? Applied Ergonomics. 1995;26(3):165-71.

[33] Nylen P, Favero F, Glimne S, Fahnehjelm KT, Eklund J. Vision, light and aging: A literature overview on older - age workers. Work. 2014;47(3):399-412.

[34] Jackson G, Owsley C, McGwin G. Aging and dark adaptation. Vision Research. 1999;39:3975-82.

[35] Collins M. The onset of prolonged glare recovery with age. Ophthalmic and Physiological Optics. 1989;9: 368-71.

[36] Bartlett H, Davies L, Eperjesi F. Reliability, normative data, and the effect of age-related macular disease on the Eger Macular Streeometer photostress recovery time. Ophthalmic and Physiological Optics. 2004;24:594-9.

[37] Barrero M, Hedge A. Computer environments for children: A review of design issues. Work. 2002;18:227-37.

[38] Jacobs K, Baker N. The association between children's computer use and musculoskeletal discomfort. Work. 2002;18:221-6.

[39] Jaiswal S, Asper L, Long J, Lee A, Harrison K, Golebiowski B. Ocular and visual discomfort associated with smartphones, tablets and computers: What we do and do not know. Clinical and Experimental Optometry. 2019. DOI: 10.1111/cxo. 12851

[40] Dirani M, Crowston J, Wong T. From reading books to increased smart device screen time. British Journal of Ophthalmology. 2019;103(1):1.

[41] Moon J, Lee M, Moon N. Association between video display terminal use and dry eye disease in school children. Journal of Pediatric Ophthalmology and Strabismus. 2014;51(2):87-92.

[42] Morgan I, Rose K. Myopia: Is the nature-nurture debate finally over? Clinical and Experimental Optometry. 2019;102:3-17.

[43] Read S, Collins M, Vincent S. Light exposure and eye growth in childhood. Investigative Ophthalmology and Visual Science. 2015;56:6799-87.

[44] Hobday R. Myopia and daylight in schools: A neglected aspect of public health? Perspectives in Public Health. 2016;136(1):50-5. 
[45] Galinsky T, Swanson N, Sauter S, Hurrell J, Schleifer L. A field study of supplementary rest breaks for data-entry operators. Ergonomics. 2000;43(5):622-38.

[46] Henning R, Jacques P, Kissel G, Sullivan A, Alteras-Webb S. Frequent short rest breaks from computer work: Effects on productivity and well-being at two field sites. Ergonomics. 1997;40(1):78-19.

[47] Balci R, Aghazadeh F. The effect of work-rest schedules and type of task on the discomfort and performance of VDT users. Ergonomics. 2003;46(5):455-65.

[48] Golebiowski B, Long J, Harrison K, Lee A, Asper L. Smartphone use and effects on tear film, blinking and binocular vision. Investigative Ophthalmology and Visual Science. 2018;59:913.

[49] Na N, Suk H. Adaptive luminance contrast for enhancing reading performance and visual comfort on smartphone displays. Optical Engineering. 2014;53(11 (November)): 113102.

[50] Long J, Rosenfield M, Helland M, Anshel J. Visual ergonomics standards for contemporary office environments. Ergonomics Australia. 2014;10(1):7.

[51] World Health Organization. Health promotion, Track 2: Health literacy and health behaviour. 2019 [21 January 2019]; Available from: https://www.who.int/health promotion/conferences/7gchp/track2/en/.

[52] Australian Commission on Safety and Quality in Health Care. Health literacy: Taking action to improve safety and quality 2014 [21 January 2019]: Available from: https:// www.safetyandquality.gov.au/wp-content/uploads/2014/08/ Health-Literacy-Taking-action-to-improve-safety-and-qual ity.pdf.

[53] Irving E, Sivak A, Spafford M. "I can see fine": Patient knowledge of eye care. Ophthalmic and Physiological Optics. 2018;38:422-31.
[54] Mårtensson L, Hensing G. Health literacy - a heterogenous phenomenon: A literature review. Scandinavian Journal of Caring Sciences. 2011;26:151-60.

[55] Nova N, Miyake K, Chiu W, Kwon N. Curious Rituals: Gestural interaction in the digital everyday. Pasasdena, California: Curiousrituals.wordpress.com; 2012. Available from: https://curiousrituals.files.wordpress. com/2012/09/curiousrituals-book.pdf.

[56] Saito S, Piccoli B, Smith M, Sotoyama M, Sweitzer G, Villaneuva $\mathrm{M}$, et al. Ergonomic guidelines for using notebook personal computers. Industrial Health. 2000;38:421-34.

[57] Straker L, Maslen B, Burgess-Limerick R, Johnson P, Dennerlein J. Evidence-based guidelines for the wise use of computers by children: Physical development guidelines. Ergonomics. 2013;53(4):458-77.

[58] Straker L, Abbott R, Collins R, Campbell A. Evidencebased guidelines for wise use of electronic games by children. Ergonomics. 2014;57(4):471-89.

[59] Wilson J. Ergonomics and participation. In: Wilson J, Corlett E, editors. Evaluation of Human Work: A practical ergonomics methodology. 2nd ed. London: Taylor \& Francis; 1995.

[60] Menozzi M, Von Buol A, Waldmann H, Kündig S, Krueger $\mathrm{H}$, Spieler W. Training in ergonomics at VDU workplaces. Ergonomics. 1999;42(6):835-45.

[61] Hägg G. Corporate initiatives in ergonomics - an introduction. Applied Ergonomics. 2003;34:3-15.

[62] Korkmaz S, Sommerich C. Facilitating student learning about ergonomics and healthy computing skills via participatory ergonomics. Work. 2009;34:439-48.

[63] Legg S, Jacobs K. Ergonomics for schools. Work. 2008;31:489-93. 